\title{
Fuel Efficiencies Through Airframe Improvements
}

\author{
Gaudy M. Bezos-O'Connor ${ }^{1}$ \\ NASA Langley Research Center, Hampton, VA 23681 \\ Mark F. Mangelsdorf ${ }^{2}$ \\ Heather A. Maliska ${ }^{3}$ \\ NASA Dryden Flight Research Center, Edwards, CA 93523 \\ Anthony E. Washburn ${ }^{4}$ \\ Richard A.Wahls ${ }^{5}$ \\ NASA Langley Research Center, Hampton, VA 23681
}

\begin{abstract}
The factors of continuing strong growth in air traffic volume, the vital role of the air transport system on the economy, and concerns about the environmental impact of aviation have added focus to the National Aeronautics Research Policy. To address these concerns in the context of the National Policy, NASA has set aggressive goals in noise reduction, emissions, and energy consumption. With respect to the goal of reducing energy consumption in the fleet, the development of promising airframe technologies is required to realize the significant improvements that are desired. Furthermore, the combination of advances in materials and structures with aerodynamic technologies may lead to a paradigm shift in terms of potential configurations for the future. Some of these promising airframe technologies targeted at improved efficiency are highlighted.
\end{abstract}

\section{Introduction}

The air transportation system is expected to expand by a factor of two or three within the next two decades. This expansion will similarly increase the contribution of aviation to climate change through emission of greenhouse gases, nitrogen oxides (NOx), water vapor and particulates unless technological advances are made to lessen the impact. These potential environmental impacts due to aviation are in conflict with the ever-increasing awareness of the need to reduce the human impact on the environment, with particular and heightened focus on global climate change. As the Next Generation Air Transportation System (NextGen) evolves to meet the projected growth in demand for air transportation, the environmental impacts of noise and emissions could limit the ability of the system to accommodate growth.

Much has already been accomplished in aviation that addresses these concerns. Although the shape and speed of commercial airliners have not changed significantly since the 1950s, many aspects of performance, such as range and fuel efficiency, as well as environmental impacts, such as noise, particulate, and NOx emissions have improved tremendously. However, more still needs to be done. Over the last 5-10 years, heightened sensitivity to, and understanding of, the impact of aviation on the environment and the reduced availability of low-cost energy have placed the spotlight directly on efficiency and reducing that environmental impact.

\footnotetext{
${ }^{1}$ Deputy Project Manager, Environmentally Responsible Aviation (ERA) Project, Integrated Systems Research Program, Mail Stop 254, AIAA Senior Member

${ }^{2}$ Chief Engineer, ERA Project, Mail Stop 4820-2A, AIAA Senior Member

${ }^{3}$ Airframe Technology Sub-Project Engineer, ERA Project, Mail Stop 4820-202, AIAA Senior Member

${ }^{4}$ Chief Technologist, ERA Project, Mail Stop 170, AIAA Senior Member

${ }^{5}$ Project Scientist, Subsonic Fixed Wing Project, Fundamental Aeronautics Program, Mail Stop 267, AIAA Associate Fellow
} 
To address the ongoing concerns about the environmental impact of aviation, NASA has set aggressive timelines with goals for noise, emissions, and fuel burn reductions as shown below in Table 1. NASA's Subsonic Transport System Level Metrics. Specifically, these goals are focused on noise reductions below the Stage 4 certification level; landing-take-off cycle (LTO) NOx emissions relative to the CAEP 6 standards; cruise NOx emissions and fuel burn reductions relative to 2005 best in class aircraft. As the metrics table demonstrates, NASA has identified near term (2015), mid-term (2020), and far-term (2025) opportunities for technology insertion, with increasingly aggressive goals for noise, emissions and fuel burn reductions at each five-year interval. These timelines are denoted as $\mathrm{N}+1$, $\mathrm{N}+2$, and $\mathrm{N}+3$ respectively, where $\mathrm{N}$ signifies the latest generation of aircraft and technology currently in operation (1997/1998). NASA's goal is to raise pertinent technologies to TRL 4-6 by these dates so that they may be used in any subsequent transport category aircraft and engine program.

\section{NASA Subsonic Transport System Level Metrics .... technology for dramatically improving noise, emissions, \& performance}

\begin{tabular}{|c|c|c|c|}
\hline \multirow{2}{*}{$\begin{array}{c}\text { TECHNOLOGY } \\
\text { BENEFITS* }\end{array}$} & \multicolumn{3}{|c|}{$\begin{array}{c}\text { TECHNOLOGY GENERATIONS } \\
\text { (Technology Readiness Level = 4-6) }\end{array}$} \\
\cline { 2 - 4 } & $\mathrm{N}+1$ (2015) & $\mathrm{N}+2(\mathbf{2 0 2 0 * *})$ & $\mathrm{N}+3(\mathbf{2 0 2 5 )}$ \\
\hline $\begin{array}{c}\text { Noise } \\
\text { (cum margin rel. to Stage 4) }\end{array}$ & $-32 \mathrm{~dB}$ & $-42 \mathrm{~dB}$ & $-71 \mathrm{~dB}$ \\
\hline $\begin{array}{c}\text { LTO NOx Emissions } \\
\text { (rel, to CAEP 6) }\end{array}$ & $-60 \%$ & $-75 \%$ & $-80 \%$ \\
\hline $\begin{array}{c}\text { Cruise NOx Emissions } \\
\text { (rel. to 2005 best in class) }\end{array}$ & $-55 \%$ & $-70 \%$ & $-60 \%$ \\
\hline $\begin{array}{c}\text { Aircraft Fuel/Energy Consumption } \\
\text { (rel, to 2005 best in class) }\end{array}$ & $-33 \%$ & $-50 \%$ & $-80 \%$ \\
\hline
\end{tabular}

* Projected benefits once technologies are matured and implemented by industry. Benefits vary by vehicle size and mission. $\mathrm{N}+1$ and $\mathrm{N}+3$ values are referenced to a 737-800 with CFM56-7B engines, $\mathrm{N}+2$ values are referenced to a $777-200$ with $\mathrm{GE} 90$ engines

** ERA's time-phased approach includes advancing "long-pole* technologies to TRL 6 by 2015

$\ddagger \mathrm{CO}_{2}$ emission benefits dependent on life-cycle $\mathrm{CO}_{2}$ per $\mathrm{MJ}$ for fuel and/or energy source used

Table 1. NASA's Subsonic Transport System Level Metrics.

Two NASA projects are using the Subsonic Transport System Level Metrics to guide technology investments. These projects are the Environmentally Responsible Aviation Project of the Integrated Systems Research Program and the Subsonic Fixed Wing Project of the Fundamental Aeronautics Program. Although they use the same metrics table for strategy, the projects are distinct. The Environmentally Responsible Aviation Project (ERA) is focused on technology development, from TRL 3-6, of technologies that contribute to the simultaneous reduction of noise, emissions and fuel burn for transport category aircraft. ERA is working to mature the technologies that are critical to simultaneous achievement of these goals by 2020 (N+2 timeframe). The Subsonic Fixed Wing Project (SFW) includes a broader research and technology portfolio guided by a fundamental set of technical challenges with focus on revolutionary tools and innovative, game-changing low TRL (nominally 1-4) technologies and concepts for reduced noise, emissions, and energy consumption. SFW takes a multi-generational approach, but with an emphasis on the far term, $\mathrm{N}+3$ timeframe.

The metrics shown in Table 1 were not determined arbitrarily. Rather they were determined through systems analysis processes with increasing rigor included in the near term goals. In each case, a baseline reference vehicle was determined to use for increments with a 1997/1998 technology set. Additional information about the methodology and application of the analysis to the Subsonic Transport System Level Metrics for the N+1, N+2 and $\mathrm{N}+3$ timeframes can be found in Collier et $\mathrm{al}^{1}$ and Nickol and McCullers. ${ }^{2}$ The $\mathrm{N}+1$ numbers were developed through unpublished internal analysis. The $\mathrm{N}+3$ energy consumption goal is based on a compilation of the $\mathrm{N}+3$ NASA Research Announcement (NRA) studies. ${ }^{3,4,5,6,7}$

As an example of what the integration of technologies into airframes are expected to be able achieve, Figure 1 below illustrates the potential impact of applying the $\mathrm{N}+2$ airframe, propulsion and acoustic shielding technologies on the hybrid wing body configuration is shown. ${ }^{1}$ The N+2 HWB configuration takes advantage of acoustic 
shielding with an integrated non-circular fuselage, blended wing and engines located above the fuselage. The predicted fuel burn reductions for the N+2 HWB configuration from the $\mathrm{N}+2$ airframe technologies result in a $31 \%$ savings and the advanced propulsion engine technologies would contribute an additional $19 \%$ reduction in fuel burn for a total of $50 \%$ fuel burn reduction.

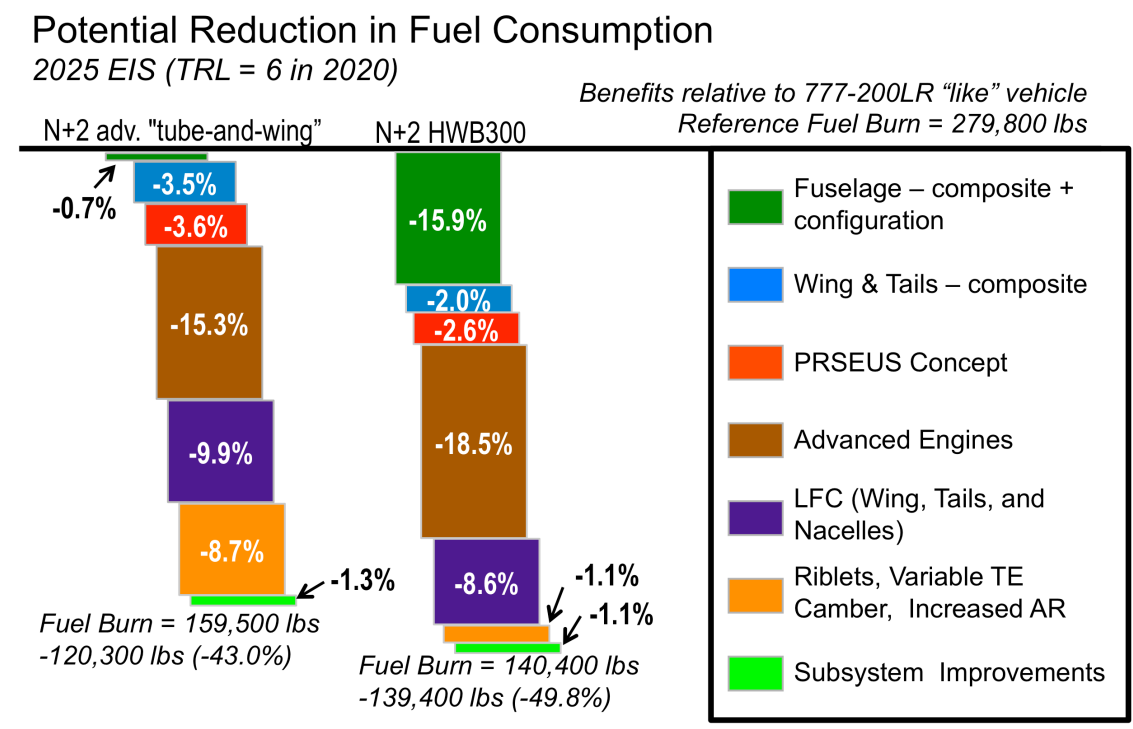

Figure 1. Waterfall chart representing the contribution of airframe technologies to reducing fuel burn for $\mathrm{N}+2$ Advance Tube and Wing and $\mathrm{N}+2$ Hybrid Wing Body (HWB) vehicle configurations.

To gain a first principles understanding of what drives the fuel consumption of an airplane, it helps to examine the Breguet Range Equation shown below.

\section{Equation 1: Breguet Range Equation}

$$
\text { Aircraft Range }=\frac{\text { Velocity }}{T S F C}\left(\frac{\text { Lift }}{\text { Drag }}\right) \ln \left(1+\frac{W_{\text {fuel }}}{W_{P L}+W_{\text {OEW }}}\right)
$$

Where:

Drag $=$ Aircraft Drag (lbf)

Lift $=$ Lift produced by the aircraft $(\mathrm{lbf})$

TSFC $=$ Thrust Specific Fuel Consumption $((\mathrm{lbf} / \mathrm{hr}) / \mathrm{lbf})$

Velocity $=$ Aircraft Velocity $(\mathrm{nm} / \mathrm{hr})$

$\mathrm{W}_{\text {fuel }}=$ Fuel Weight (lbf)

$\mathrm{W}_{\mathrm{PL}}=$ Payload Weight $(\mathrm{lbf})$

$\mathrm{W}_{\mathrm{OEW}}=$ Operating Empty Weight $(\mathrm{lbf})$

Equation 1 shows that if the speed and TSFC (an engine parameter) are constant, to fly a given payload as far as you can on a given amount of fuel, the lift to drag ratio (L/D) must be maximized and the operating empty weight $\left(\mathrm{W}_{\mathrm{OEW}}\right)$ must be minimized. In cruise flight, Lift $=$ Weight, therefore maximizing $\mathrm{L} / \mathrm{D}$ requires minimizing drag. Since the largest contributor to operating empty weight is the aircraft's structural weight, most efforts to reduce empty weight focus on the reducing the weight of the aircraft's main structural components.

NASA is collaborating with other government agencies, industry and academia to achieve the common goal of reducing the environmental impact of aviation. NASA is a collaborator with the FAA in its Continuous Lower Energy, Emissions and Noise (CLEEN) Program to target technologies in the N+1 timeframe that will reduce all 
three environmental impacts. NASA is continuing its long-standing collaboration with the Air Force Research Laboratory (AFRL) on many areas of research of interest to both parties. NASA is also working closely with industry and academia to develop technologies that will reduce noise, emissions and fuel burn as well as assess the impacts that these technologies will have on the environment fleet-wide.

This paper provides a brief description of promising technologies, focused mainly on those that reduce drag and weight, and their potential contributions to enable future transport aircraft to meet the challenging NASA Subsonic Transport Level Metrics for energy consumption. A brief highlight on $\mathrm{N}+3$ advanced vehicle configurations and airframe technologies are also presented.

\section{Aerodynamic Technologies for Energy Efficiency}

As illustrated by the Breguet range equation, technologies are sought that reduce drag while enabling an increase in the Lift to Drag ratio (L/D) with little or no penalty in cruise speed to improve efficiency. There are several contributors to overall aircraft drag that are targets for reduction. The largest contributor to modern transport aircraft drag is viscous or friction drag. The next largest contributor to the overall drag is the induced drag or the drag created due to the lifting force on the aircraft. Together, these two categories account for approximately $85 \%$ of the total cruise drag on a long-haul transport and $75 \%$ on business jets. ${ }^{8,9}$ The next two largest contributors to cruise drag are interference drag, caused by unfavorable interactions on aircraft configurations, and wave drag, caused by supercritical flow on aircraft flying at high subsonic speeds. These two drag categories range from approximately $5 \%-10 \%$ and $3 \%-10 \%$ respectively. We will focus primarily on viscous drag, wave drag, and induced drag from an aerodynamic technology viewpoint. Bushnell ${ }^{10}$ gives a more in depth summary of aircraft drag reduction opportunities with a comprehensive reference list.

\section{A. Technologies Targeted at Viscous Drag Reduction}

Since viscous drag contributes approximately $50 \%$ of the total drag of a typical transport aircraft, improvements in this area are very beneficial. There are three main approaches available to reduce viscous drag. One approach is to pursue techniques to reduce the overall aircraft surface area for a given mission, thus reducing the "wetted" area. The second approach is to manage and reduce the skin friction of a turbulent boundary layer. The third and probably most promising technology suite for large reductions in viscous drag is to prevent large portions of the flow over wings, empennages, and nacelles from undergoing laminar to turbulent transition, thereby significantly reducing the local skin friction.

The reduction of wetted area can be accomplished through innovative configurations like a Hybrid Wing Body (HWB) or by improving the aerodynamic performance of aircraft components so that smaller surfaces are possible. One approach with promise is to use active flow control to improve lifting surface performance. Active flow control can be done in a number of ways. One approach is to use unsteady excitation to the flow to eliminate or reduce the negative effects of flow separation. This allows the surface to generate more lifting force with less drag. One potential example application is to enhance high-lift system performance to eliminate/reduce flap support structure fairings. ${ }^{11}$ Another is to increase rudder effectiveness and reduce the overall size of the empennages. ${ }^{12}$ In both cases, the active flow control system is not used for most of the mission but enhances capability for short periods of time. The NASA ERA project and The Boeing Company are jointly exploring the possible increment to the rudder effectiveness using this technique and assessing the system trades for implementation. Another older method to generate circulation around surfaces is to take advantage of the Coanda effect with blowing. This technique is commonly called circulation control.

The reduction of drag in the presence of a turbulent boundary layer is also of key interest in aeronautics, because there are many flow situations where it is either not possible or not desirable to maintain a laminar boundary layer. In these instances there are opportunities to reduce the drag due to the skin friction at the surface. These techniques include both active and passive alteration of the coherent structures present in turbulent boundary layers. Active techniques range from wall injection, to directly interact with the structures, to moving waves and oscillating walls to organize the structures in the boundary layer. Passive techniques can also be used. For example, designing surfaces to reduce the near-wall longitudinal momentum without inducing flow separation is one such technique. Another and perhaps the most well know passive techniques is known as riblets. ${ }^{13,14}$ These structures reduce the local skin friction by $6 \%-8 \%$ by imposing a span-wise constraint of the flow through the use of small grooves in the surface. Flight demonstrations of riblets have been conducted and have demonstrated a $1 \%-2 \%$ reduction in viscous drag at flight conditions and scales but more development is required to make them economically viable. ${ }^{15}$

The approach to reduce viscous drag by maintaining a laminar boundary layer over large portions of the aircraft is probably the most mature technique in terms of theory and demonstration. Systems studies show that reduction in 
energy consumption of up to $10 \%$ may be possible with successful application of laminar flow alone. In order to maintain laminar flow over a swept wing aircraft, three transition mechanisms must be managed or controlled. The three mechanisms are attachment line transition, a time-dependent viscous based transition mechanism (TollmienSchlichting), and an inviscid instability transition mechanism (crossflow). At large wing sweep angles, the sensitivy to attachment line transition and the crossflow instability is increased. Therefore, from an aerodynamic perspective, multiple approaches to achieve laminar flow are promising and the selection of such is dependent on the mission and other design variables such as wing sweep, Reynolds number, and high lift system integration. For moderately high Reynolds numbers (such as the Airbus A320 or Boeing B737) and low to modest leading edge sweep angles, the technique known as Natural Laminar Flow (NLF) is considered possible. This technique uses passive shaping to control the wing pressure field and manage the pertinent transition mechanisms. For large Reynolds numbers and/or larger sweep angles, Hybrid Laminar Flow Control (HLFC) via suction is the most robust approach, but it adds additional system-level requirements such as suction systems and small holes in the leading edge. The third approach is another hybrid laminar flow control technique that uses a combination of shaping to manage the Tollmein-Schlicting transition mechanism and control of cross-flow transition mechanism through the use of Discrete Roughness Elements (DRE). These roughness elements are on the order of a few microns in effective height and are spaced a few millimeters apart just downstream of the attachment line. They introduce streamwise vorticity that inhibits the growth of the naturally occurring and unstable vortices that normally lead to cross-flow transition.

There has been much activity in laminar flow control approaches over the years with numerous references, ${ }^{16,17,18,19}$ and many flight experiments. ${ }^{20,21}$ Although much progress has been made to apply laminar flow on wings engine nacelles (B787 has NLF on the engine nacelles ${ }^{22}$ ) and tails (B787-9, a stretched version will have hybrid LFC on the horizontal and vertical tails ${ }^{23}$ ) significant questions as to optimized design and integration processes, streamlined manufacturing approaches, and long term operational viability have delayed adoption to the subsonic transport fleet. ${ }^{15}$

The NASA ERA Project is sponsoring a flight test of the DRE approach to laminar flow control. The technique is described by Saric, Carpenter, and Reed ${ }^{24}$ and appears to be a very promising method to passively control the cross-flow instability on swept wings. This technology has been demonstrated at Reynolds numbers of 8 million in previous flight tests, therefore, the purpose of the current activity is to demonstrate DRE technology to Reynolds numbers of 15-20 million. The DRE will be applied on a specially designed wing glove mounted on a NASA Dryden Gulfstream G-III aircraft. ${ }^{25,26}$ The goal of this experiment is to obtain an understanding of the application of DRE at moderate Re numbers, and takes an important step in assessing their feasibility at higher-chord Re numbers typical of large transonic transport aircraft.

\section{B. Technologies Targeted at Wave Drag Reduction}

The reduction of wave drag on a transonic wing typical of transport aircraft can be done via favorable shockboundary layer interactions in the region where the shock impinges on the aft wing surface. Typically wings are designed with very little wave drag at design conditions, but when the vehicle operates off of the design condition significant improvements can be envisioned. Alternately, if shock/boundary layer interaction can be controlled, more aggressive wings can be utilized to further extend upper surface laminar flow without shock induced separation or wing buffet. One such technique using pulsed vortex generator jets is described by Tilmann ${ }^{27}$ and has demonstrated improvements in L/D over a wide range of conditions. Another approach that is aerodynamically effective is to use a variable camber wing/trailing edge to control shock impingement in flight. A related demonstration was recently conducted by the NASA SFW Project showing that small amounts of blowing through a small slot upstream of a stowed flap was effective to control the shock impingement through modification of the wing circulation. This demonstration was done at flight Reynolds numbers with a system also designed for high lift circulation control. Another approach attempted in the past is known as passive porosity and used a porous surface over a shallow cavity in the wing in the vicinity of the shock impingement to relieve the pressure across the shock and weaken the wave drag. The porous surface acted like a compression ramp to spread the shock. The technique did reduce wave drag, but also resulted in a corresponding increase in viscous and pressure drag due to the formation of a thick boundary layer downstream of the shock. An alternative approach that has been demonstrated with favorable results is the use of a small adaptive bump in the shock vicinity. ${ }^{28,29}$ In practice the bump, which has a small height requirement, would be deployed to delay the drag rise when the wing is flying at off design conditions. Another intriguing approach to delay the drag rise and increase the ML/D of a wing is to use a cruise slotted flap ${ }^{30}$ to move the shock aft and use the flap as a trailing edge camber device with a robust boundary layer on the flap to control shock induced separation. The tolerances for such a device are tight, but the capability has been 
demonstrated through a cooperative partnership between NASA and Boeing in 3D with a slotted flap at cruise which was also successfully used as a single flap high lift system. In the end, it is likely that wings will continue to be designed with a small amount of wave drag at cruise, but as technologies such as some described above are realized, the benefit will be taken via some combination of reduced sweep, increased speed, increased airfoil thickness and/or increased lift coefficient.

\section{Technologies Targeted at Induced Drag Reduction}

The two passive design techniques that are typically used to reduce induced drag are to increase the wing span or to design the span-wise lift distribution such that the induced drag is minimized. The equation for the induced drag coefficient shown as Equation 2, can be reduced to the equation for the induced drag shown as Equation 3. Equation 3 shows how both of these mechanisms work.

\section{Equation 2:}

$$
C_{D i}=\frac{C_{L}^{2}}{\pi e A R}
$$

Equation 3:

$$
D_{\mathrm{i}}=\frac{1}{q \pi e}\left(\frac{L}{b}\right)^{2}
$$

Where:

$$
\begin{aligned}
& \mathrm{CDi}=\text { Induced Drag Coefficient } \\
& \mathrm{CL}=\text { Lift Coefficient } \\
& \Pi=3.1415 \ldots \\
& \mathrm{e}=\text { Oswald's span efficiency factor } \\
& \text { AR }=\text { Aspect Ratio }=\mathrm{b}^{\wedge} 2 / \mathrm{S} \\
& \mathrm{b}=\text { wing span }(\mathrm{ft}) \\
& \mathrm{S}=\text { wing reference area }(\mathrm{ft} \wedge 2) \\
& \mathrm{q}=\text { dynamic pressure }=1 / 2 \rho \mathrm{V}^{2} \\
& \mathrm{~L}=\text { lift }(\mathrm{lbf}) \\
& \rho=\text { density }\left(\text { slugs } / \mathrm{ft}^{3}\right) \\
& \mathrm{V}=\text { velocity }(\mathrm{ft} / \mathrm{sec})
\end{aligned}
$$

Max Munk ${ }^{31}$ showed that the minimum induced drag of a fixed span wing occurs when the wing has a constant downwash along the span and that this condition occurs when the span-wise lift distribution is elliptical. When the span-wise lift distribution is elliptical and the wing is planar, Oswald's span efficiency (e) reaches it's maximum value of 1 . Therefore, for a fixed span, planar wing, if the span-wise lift distribution is elliptical, the induced drag is at a minimum. Further reductions in induced drag require either span increases or changing to a non-planar wing.

Cone $^{32}$ showed theoretically that non-planar wings can reduce the drag by as much $30 \%$. Whitcomb ${ }^{33}$ put the theory into practice and developed the first practical winglet design. In recent years many studies have been done on ideas that extend the idea of winglets even further; into C-wings and into variations of bi-planes such as joined and box wing configurations. All of these non-planar configurations show increasing reductions in induced drag as the height of the winglet or gap between the upper and lower wing increases.

The other passive method to reduce the induced drag is to simply increase the span. By increasing the span, the span loading, L/b, decreases, and with it, the induced drag. The challenge with increasing the span is that the structural weight of the wing increases rapidly with increasing span. R.T. Jones ${ }^{34}$ approached this problem by showing that when the fixed span constraint is replaced with a constant root bending moment constraint, a first order driver of wing weight, the optimum span-wise lift distribution is no longer elliptical. This new optimum span-wise 
lift distribution results in a wing that has the same root bending moment as the elliptical wing, hence roughly the same weight, with more span and hence less induced drag.

While increasing the span to reduce induced drag is attractive, at some point the weight increases due to the increased span negate the induced drag benefit. Some version of this also holds true for the various non-planar wing configurations; winglets and C-wings add weight, which increases as the winglet increases in height. One approach to reducing the weight penalty for large span wings is active control of the span-wise lift distribution.

The addition of active controls to control the lift distribution, typically through gust load alleviation, allows multiple 'optimum' wing designs. The structural weight of the wing is largely driven by the span-wise location of the centroid of lift, i.e. the root bending moment. If this centroid can be moved inboard for a given amount of lift, the structural weight required to support that lift can be reduced. Since the critical design load cases for a transport category aircraft wing are at maneuvering and gust conditions, and induced drag should be minimized for the cruise condition, both can be optimized through the use of active controls. Using control surfaces to move the lift centroid inboard at maneuvering conditions or to reduce the gust load that the wing has to be designed for by dumping lift in gust conditions can have a powerful ability to reduce wing weight. Lockheed used this technique to increase the span of the L-1011 by $5 \%$ with essentially no increase in wing root bending moment. ${ }^{35}$

As shown above, every technique used to reduce induced drag either adds weight, span increases or non-planar wings, or complexity, active controls. To reduce the weight penalty of these drag reduction techniques, the aircraft designer increasingly turns towards new materials and structural concepts that promise the ability to reduce this weight penalty by increasing strength, stiffness or decreasing the density of the structural material.

\section{Structural Technologies for Energy Efficiency}

Weight reduction, as highlighted in the Breguet Range Equation (Equation 1) is one of the key technology areas requiring significant progress to enable the challenging fuel burn reduction goals set forth in Table 1. In particular, NASA is directly addressing the operating empty weight (OEW) portion of overall weight. New metals and new composites are being researched as are the integration of the new and existing materials in to new structural concepts. Prevalent themes are the development of unitized, tailored, and/or multifunctional and adaptive materials and structures. It is also recognized that an effective solution requires not only improved material/structural properties, but also a technically and economically viable design and manufacturing solution as well. This section will highlight several areas of research.

\section{A. Stitched Composites}

The ERA and SFW Projects are focused on the development of low-cost, lightweight composite structures for transport aircraft. Stitching applied to composites offers a key solution to a barrier challenge that heretofore has limited the potential weight benefits of composite structures - damage tolerance. Without stitching, due to reduced damage tolerance as compared to metals, composite structures are typically designed in a safe-life rather than a failsafe manner; this means ultimate design loads are significantly reduced for the unstitched composite compared to an equivalent metal structure. To compensate, the composite structure grows in weight to achieve the same ultimate load as the metal. Stitching provides the key to arresting damage growth in a manner to enable realization of the more of the potential weight savings of composite structures.

NASA has pursued the development of stitched composite structures over the last two decades. Most recently, collaboration with Boeing and AFRL has produced a very promising concept. Velicki and Jegley ${ }^{36}$ highlight a specific application of stitched composite technology, named Pultruded Rod Stitched Efficient Unitized Structure (PRSEUS), for the design of a hybrid wing body. In this concept a stitched carbon-epoxy material system is used. By stitching through the thickness of a dry carbon fabric, the labor associated with panel fabrication and assembly can be significantly reduced. When stitching through the thickness of pre-stacked skin, stiffeners, and other elements, the need for mechanical fasteners is nearly eliminated. This manufacturing approach enables large unitized structures and reduces part count contributing to reducing the cost of the structure. In addition, stitching reduces de-lamination and improves damage tolerance. PRSEUS, and other stitched composite structural concepts, is broadly applicable to aircraft structure, including both wing and fuselage structures of conventional and unconventional configurations, and is particularly well-suited, in fact enabling, to an HWB-centerbody application providing a solution to the non-circular pressure vessel challenge. In this application, studies have indicated a $10.3 \%$ weight reduction compared to advanced composite sandwich structure analytically applied to a non-circular centerbody shell, and manufacturing cost savings (based on experience with a similar but non-primary structural application). 


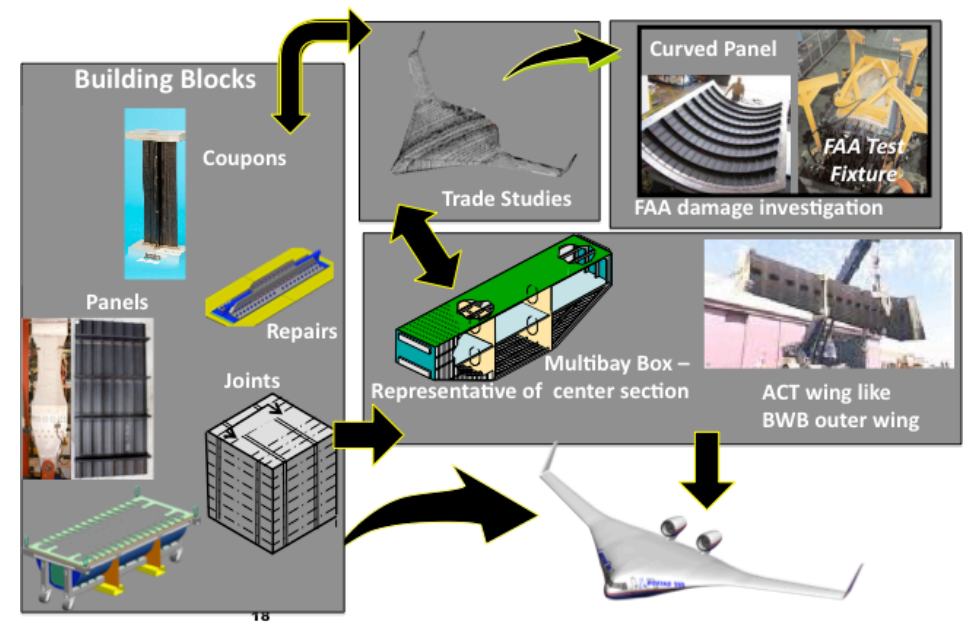

Figure 2. PRSEUS Development Roadmap depicts the building block approach.

To realize the potential of PRSEUS, a building block approach has been utilized in its development as shown in Figure 2. Testing has been conducted on coupons, elements, and subcomponents, and will culminate in testing of full-scale components. Several flat PRSEUS panels were designed, fabricated, and tested originally under a SFW Project NRA task. Technology maturation is continuing in the ERA project were gaps in manufacturing and structural integrity associated with the design and fabrication of large-scale aircraft components are being addressed. The strategy includes conducting internal pressure testing (compression panels, wing box-like multi-bay test article), joint design and pressure testing of a cube, large-scale curved panel test in partnership with the FAA Tech Center, large scale dynamic evaluations, fatigue and thermal evaluations. The culmination of the ERA Project Phase 1 Portfolio for the PRSEUS technology is the development of a large-scale, multi-bay, pressurized fuselage box. This noncircular pressurized fuselage section will be tested to failure under biaxial in-plane loadings, as well as out-ofplane pressure loadings typical of transonic transport aircraft at the NASA LaRC Combined Loads Test (COLTS) Facility in the late FY12/early FY13 timeframe. If successful, this test will take PRSEUS to a TRL of 5, significantly reducing risk as an enabling technology for a HWB transport configuration or for use on a conventional configuration.

\section{B. Electron Beam Free Form Fabrication $\left(\mathbf{E B F}^{3}\right)$}

While composite technology is making significant advances, metals are more appropriate for many airframe applications and continue to require research. One enabling technology for is known as Electron Beam Freeform Fabrication $\left(\mathrm{EBF}^{3}\right)$ - a crosscutting technology advance in layered part (or additive) fabrication for producing structural metal parts. Developed by researchers at $\mathrm{NASA}^{37}$ as a replacement for forgings, this manufacturing process offers significant reductions in cost and lead-time, and potential for significant reductions in weight. $\mathrm{EBF}^{3}$ uses a focused electron beam in a vacuum environment to create a molten pool on a metallic substrate. $\mathrm{EBF}^{3}$ works in a vacuum chamber, where an electron beam is focused on a constantly feeding source of metal, which is melted and then applied as called for by a drawing — one layer at a time - on top of a programmed moving surface until the part is complete. First, the drawing is needed to break up the object/part into layers, with each cross-section used to guide the electron beam and source of metal in reproducing the object/part, building it up layer by layer. Second, the material must be compatible with the electron beam so that it can be heated by the stream of energy and briefly turned into liquid form, making aluminum an ideal material to be used, along with other metals. A novel capability of the $\mathrm{EBF}^{3}$ process is that it can handle two different sources of metal at the same time, either by mixing them together into a unique alloy or embedding one material inside another. The potential use for the latter could include embedding a strand of fiber optic glass inside an aluminum part, enabling the placement of sensors in areas that were impossible before. The layer-additive process enables fabrication of parts directly from CAD drawings; metal is placed only where it is needed saving weight by design, and the material chemistry and properties can be tailored throughout a single-piece structure, leading to new designs for integrated sensors, tailored structures, and complex, curvilinear stiffeners. To realize the full potential of this manufacturing technology, new design tools are required that are not tied to previous design paradigms; such design tool development has been described by Kapania ${ }^{38}$ and development has continued via an SFW NASA Research Announcement (NRA) award. The parts can be designed to 
support loads and perform other functions such as aeroelastic tailoring or acoustic dampening. There is great potential for the process in developing major structural segments of an aircraft, or casings for a jet engine, that could be manufactured for about $\$ 1,000$ per pound less than conventional means. Environmental savings also are made possible by deploying $\mathrm{EBF}^{3}$, using only the material necessary for the part, which translates into less waste.

\section{Compliant Flaps and Multi-Objective Leading-Edges}

A variety of concepts to eliminate flap, slat, and control surface slots and gaps have been conceptualized over the years. The motivations are varied, from eliminating noise sources to improved aerodynamic performance or more effective control, but the practical challenge often lies in the material/structural characteristics. In some cases, specifically for the leading-edge concepts, the goal is to enable sufficient off-design (high-lift) performance in a system that is completely invisible when not deployed at cruise conditions, thus facilitating the maintenance of clean external lines for laminar flow. Such multi-objective leading-edge concepts (MOLEC) have been studied NASA SFW researchers and by industry under SFW contract with results summarized by Turner. ${ }^{39}$ Approaches include structures that enable slat-cove fillers, slat-gap fillers, and drooped, gapless leading-edges, as shown in example Figure 3 below.

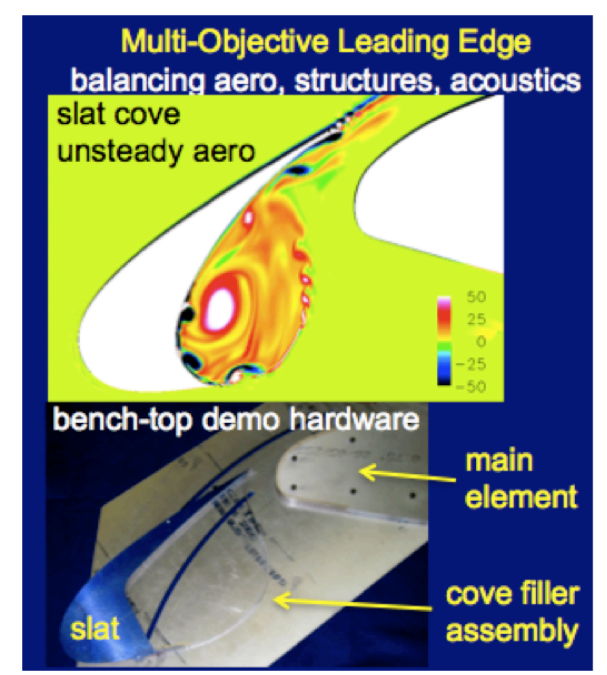

Figure 3. An example of a multi-objective leading edge: slat cove with filler assembly.

Additionally, under the current SFW N+3 phase 2 studies, Northrop Grumman is advancing MOLEC concepts developed under NASA SFW, and AFRL funding, culminating in a low-speed aerodynamic test of down-selected, preferred concepts in FY12.

Similar to the work on leading-edge concepts, research has been conducted by NASA SFW and AFRL focused on trailing-edge concepts. ${ }^{40}$ One such concept has been advanced by AFRL which developed and flight demonstrated a section of compliant trailing edge flap that could be utilized as a trim device and as a high rate control surface and gust load alleviation device. This flight demonstration validated the use of the flap to maintain large amounts of laminar flow over a broad range of lift coefficient, and also demonstrated the use of the flap to +/10 degrees of deflection at actuation rates of 30 degrees per second. The demonstration used a 50" span and 30" chord wing test fixture with a $30 \%$ compliant trailing edge flap. AFRL and NASA ERA are currently teaming to fly the compliant trailing edge flap concept on a NASA GIII aircraft. The compliant trailing edge flaps enable trim, improved control effectiveness, load alleviation, and high lift while incurring little or no weight penalty nor control power penalty versus a traditional hinged surface. In addition, compliant flaps have the potential to achieve large deflections, are able to vary deflection along the span (twist) and utilize the flap as a multipurpose surface across the entire flight envelope. The flight test of the compliant trailing edge flap on the NASA GIII is scheduled in the late FY14 timeframe. 


\section{Advanced Integrated Wing}

Figure 4 (shown below) provides a pathway towards an advanced integrated wing concept, essentially a vision wing that research can drive towards in coming years. The upper left image is representative of a unitized structure designed with curvilinear stiffeners. This type of structure is enabled by $\mathrm{EBF}^{3}$ manufacturing and new design tools.

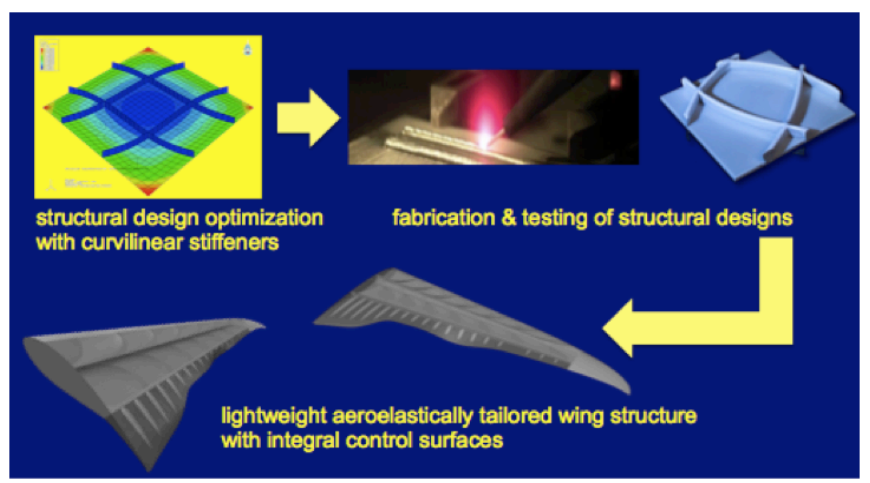

Figure 4. Electronic Beam Free Form Fabrication $\left(\mathrm{EBF}^{3}\right)$ manufacturing for advanced wing concepts.

On the top right of Figure 4 is a piece of hardware that has been fabricated with $\mathrm{EBF}^{3}$ for evaluation. Ultimately, the vision is to create new lightweight aeroelastically tailored wing structures that may have curvilinear, perhaps bioinspired internal structures and skin with gapless, conformal mold line leading and trailing edges that reduce noise in addition to being light weight. Two views of such a futuristic wing are shown at the bottom, where some of the internal structure is shown as well.

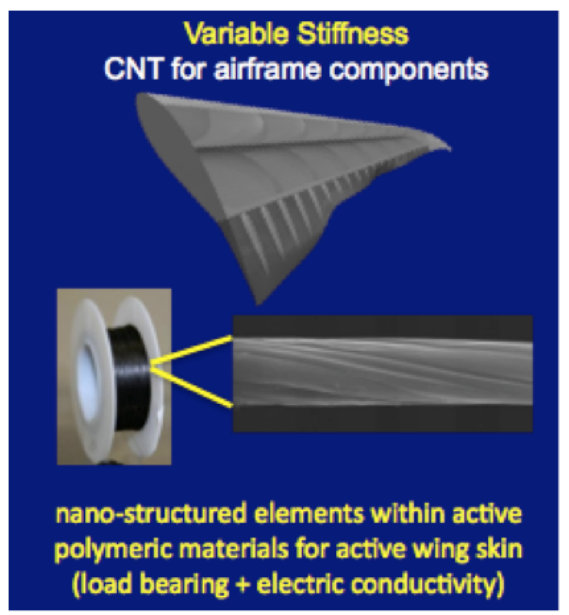

Figure 5. Carbon-nanotube material applications for airframe components.

Figure 5 highlights that advanced multifunctional materials will be required to reach the ultimate vision. Commercial-scale carbon nanotube (CNT) yarn is now available and being researched for small-scale applications. The key with CNT is that they can provide both load-bearing structure/skin with electric conductivity - enabling active polymeric materials for active skin applications. The images show the concept wing from Figure 4, and below it, a spool of CNT yarn. The potential of nanotubes is enormous, theoretically offering several orders of magnitude increase in strength. At present, tested strength is nowhere near the theoretical limits and research continues.

\section{Vehicle/Technology Integration for Energy Efficiency}

Airframe technologies along with propulsion and operations technologies will be combined, traded, and ultimately packaged into the integrated vehicles of the future. Most of the airframe technologies under study are broadly applicable to any conventional or unconventional configuration; few are uniquely enabling for specific vehicle 
concepts. NASA uses vehicle concepts to drive the understanding of system and subsystem level interdependencies and integration amongst various technologies, and as technology collectors to explore and demonstrate what is possible in the future. Currently, the ERA Project is in the midst of funded studies with industry to explore and develop vehicle and technology concepts to simultaneously meet the mid-term $\mathrm{N}+2$ goal set in Table 1; initial studies are scheduled for completion in FY12. The SFW Project is focused on the far-term N+3 goal set in Table 1, and has completed Phase 1 of NRA-funded studies addressing vehicle concepts and enabling technologies; currently phase 2 research addressing high priority/high impact technology research is ongoing. Additionally, in-house research has identified unconventional configurations and enabling technologies as well., ${ }^{3,4,5,6,7}$

Figure 6 below shows several representative examples of aircraft configurations, bringing together advanced technology unconventional airframes and unconventional propulsion systems to realize revolutionary performance in terms of noise, emissions, and energy efficiency. The top left aircraft is known as the Boeing SUGAR VOLT, and was produced by a Boeing-led team in the SFW N+3 NRA advanced concepts study. It is a truss-braced wing aircraft with a hybrid gas turbine/electric propulsion system. Beyond advanced materials, laminar flow, and load alleviation technologies, this concept relies on significant aero-structural integration to realize a lightweight, low drag wing-strut system. The top right aircraft in Figure 6 was conceptualized in-house by NASA SFW researchers and is known as the N3-X. It is a hybrid wing body configuration with a turbo-electric, distributed propulsion system where tip mounted core engines drive-distributed fans. The bottom image is the D8 Double Bubble configuration with a high by-pass ratio, boundary layer ingesting propulsion system, and thin, mostly turbulent high aspect ratio wings. This was produce by a MIT-lead team in the NASA N+3 advanced concepts study. Like the SUGAR VOLT, each configuration relies on advanced materials, structural concepts, and highly integrated propulsion/airframe integration that must be quiet and produce minimal interference/installation drag. Additional details on these $\mathrm{N}+3$ Vehicles studies and others can be found in references 3 through 7 and ${ }^{41}$.

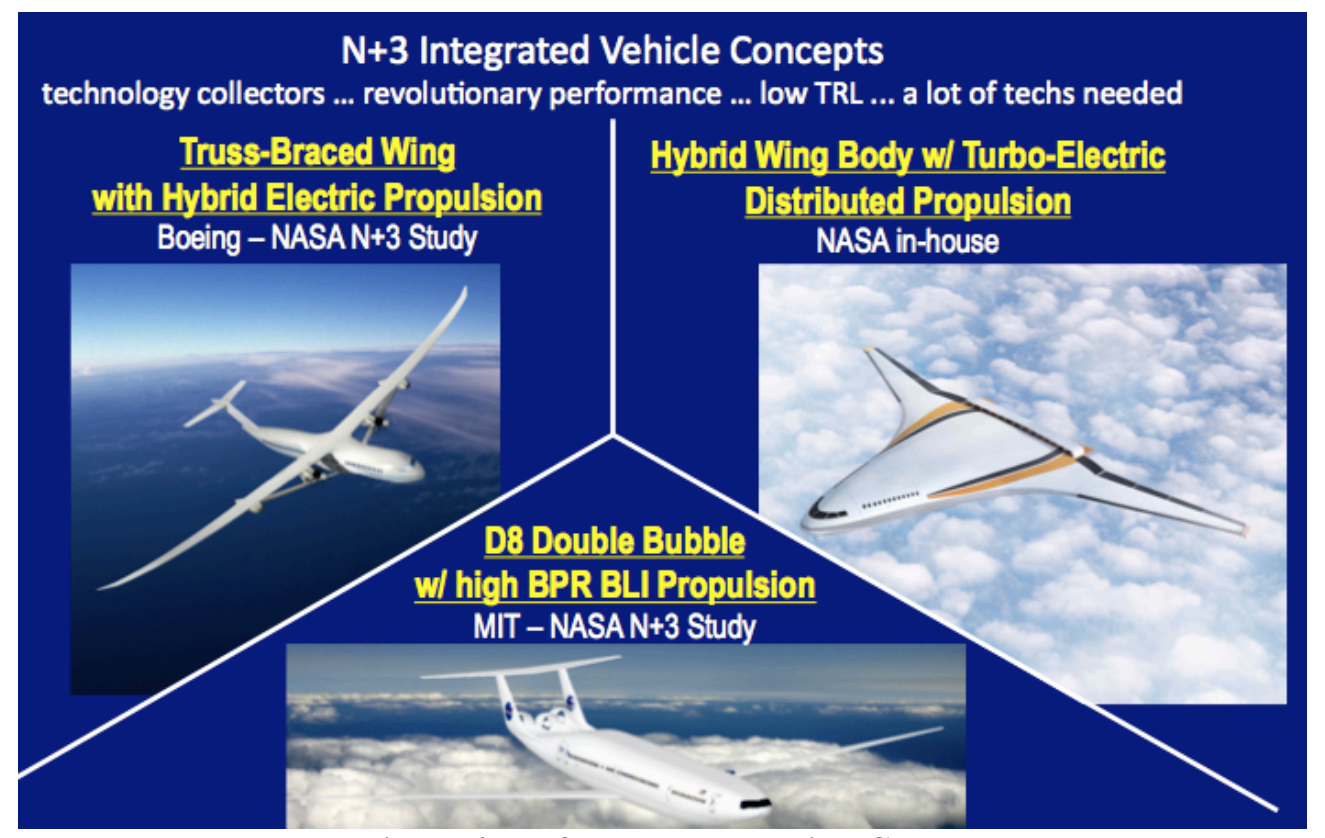

Figure 6. N+3 Integrated Vehicle Concepts.

\section{Concluding Remarks}

Over the last 5-10 years, heightened sensitivity to, and understanding of, the impact of aviation on the environment and the reduced availability of low-cost energy have placed the spotlight directly on efficiency and reducing that environmental impact. This paper has provided a brief overview of the most promising airframe technologies, focused mainly on those that reduce drag and weight, and their potential contribution to enable future subsonic transport aircraft to meet NASA's Subsonic Transport Level Metrics for energy consumption. NASA has prepositioned its development effort into five-year technology insertion windows, near term (2015), mid-term (2020), and far-term (2025) with increasingly aggressive goals at each five-year mark. 
NASA's Subsonic Fixed Wing (SFW) Project under the Fundamental Aeronautics Program and the Environmentally Responsible Aviation (ERA) Project under the Integrated Systems Research Program, are collaborating with other government agencies, industry and academia to develop technologies that will reduce noise, emissions and fuel burn as well as assess the impacts that these technologies will have on the environment fleet wide. An overview of innovative manufacturing processes (PRSEUS and EBF3) was presented highlighting the potential benefits of new metals and new composites and how their integration into advanced structural concepts enable significant savings in material and aircraft manufacturing costs and weight reduction resulting in fuel burn efficiency gains on the order of $16 \%$ to $20 \%(\mathrm{~N}+2$ system analysis). An overview of the promising aerodynamic techniques and technologies that NASA is investigating to control and reduce drag was also discussed. These aerodynamic technologies have the potential to significantly reduce the overall drag of the vehicle resulting in fuel burn efficiency gains on the order of $10 \%$ to $20 \%(\mathrm{~N}+2$ system analysis) depending on the vehicle configuration and level of system integration. In conclusion, significant gains in fuel burn efficiencies across vehicle and mission classes, i.e. cargo, military and passenger aircraft (Large Twin Aisle, Large Single Aisle..) can be realized through the advancement of the materials, structures and aerodynamic technologies highlighted in this paper.

\section{Acknowledgements}

The authors wish to thank the ERA and Subsonic Fixed Wing project teams for contributions to this paper.

\section{References}

\footnotetext{
${ }^{1}$ Collier, F. S., Thomas, R, Nickol, C. A., Lee, Chi-Ming, Tong, M. "Environmentally Responsible Aviation- Real Solutions for Environmental Challenges Facing Aviation, $27^{\text {th }}$ International Congress of the Aeronautical Sciences, Paper No. 802, Nice France, 19-24 September, 2010.

${ }^{2}$ Nickol, C.L, McCullers, L.A., "Hybrid Wing Body Configuration System Studies", AIAA 2009-931, January 2009

${ }^{3}$ Greitzer, E.M.; Bonnefoy, P.A.; De la Rosa Blanco, E.; Dorbian, C.S.; Drela, M.; Hall, D.K.; Hansman, R.J.; Hileman, J.I.; Liebeck, R.H.; Lovegren, J.; Mody, P.; Pertuze, J.A.; Sato, S.; Spakovsky, Z.S.; Tan, C.S.; Hollman, J.S.; Duda, J.E.; Fitzgerald, N.; Houghton, J.; Kerrebrock, J.L.; Kiwada, G.F.; Kordonowy, D.; Parrish, J.C.; Tylko, J.; Wen, E.A.; and Lord, W.K.:”N+3 Aircraft Concept Designs and Trade Studies, Final Report: Volume 1," NASA/CR-2010-216794/Vol1, December 2010

${ }^{4}$ Greitzer, E.M.; Bonnefoy, P.A.; De la Rosa Blanco, E.; Dorbian, C.S.; Drela, M.; Hall, D.K.; Hansman, R.J.; Hileman, J.I.; Liebeck, R.H.; Lovegren, J.; Mody, P.; Pertuze, J.A.; Sato, S.; Spakovsky, Z.S.; Tan, C.S.; Hollman, J.S.; Duda, J.E.; Fitzgerald, N.; Houghton, J.; Kerrebrock, J.L.; Kiwada, G.F.; Kordonowy, D.; Parrish, J.C.; Tylko, J.; Wen, E.A.; and Lord, W.K.:'N+3 Aircraft Concept Designs and Trade Studies, Final Report: Volume 2: Appendices - Design Methodologies for Aerodynamics, Structures, Weight, and Thermodynamic Cycles," NASA/CR-2010-216794/Vol21, December 2010

${ }^{5}$ D’Angelo, M.M.; Gallman, J.; Johnson, V.; Garcia, E.; Tai, J.; and Young, R.:”N+3 Small Commercial Efficient and Quiet Transportation for Year 2030-2035,” NASA/CR-2010-216691, May 2010.

${ }^{6}$ Bradley, Marty K.; and Droney, Christopher K.: "Subsonic Ultra Green Research: Phase 1 Final Report," NASA/CR-2011216847, April 2011.

${ }^{7}$ Bruner, S.; Baber, S.; Harris, C.; Caldwell, N.; Keding, P.; Rahrig, K.; Pho, L.; and Wlezian, R.: "NASA N+3 Subsonic Fixed Wing Silent Efficient Low-Emissions Commercial Transport (SELECT) Vehicle Study," NASA/CR-2010-216798, November 2010.

${ }^{8}$ Bushnell, D.M. and Hefner, J.N., "Viscous drag reduction in boundary layers", Progress in Astronautics and Aeronautics, Vol. 123, AIAA, 1990

${ }^{9}$ Marec, J-P., "Drag Reduction: a Major Task for Research", CEAS/DragNet European Drag Reduction Conference 2000, Potsdam, June 2000

${ }^{10}$ Bushnell, D. M., "Aircraft Drag Reduction - A Review," Journal of Aerospace Engineering, vol. 217, no. 1, pp. 1-18, January, 2003.

${ }^{11}$ McLean, J. D.; Crouch, J. D.; Stoner, R. C.; Sakurai, S.; Seidel, G. E.; Feifel, W. M.; and Rush, H. M., "Study of the Application of Separation Control by Unsteady Excitation to Civil Transport Aircraft," NASA/CR-19990209338, June 1999.

${ }^{12}$ N. Rathay, M. Boucher, M. Amitay and E. Whalen, "Performance Enhancement of a Vertical Stabilizer using Synthetic Jet Actuators", 1000 Islands Fluid Dynamics Meeting. Gananoque, Ontario, Canada, April 2011.

${ }^{13}$ Walsh, M. J., "Riblets," AIAA Progress in Astronautics and Aeronautics, 1990, no. 123, pp. 203-261.

${ }^{14}$ Crawford, C. H.; Chu, D. C.; and Karniadakis, G. E., Laminar and Turbulent Flow Over Optimal Riblets," Proceedings of the 1992 European Computational Fluid Dynamics Conference, Brussels, Belgium, Sept. 1992, pp. 191-198.

${ }^{15}$ Spalart, P. R., McLean, J. D., "Drag Reduction: Enticing Turbulence, and Then an Industry", Phil. Trans. R. Soc. A 2011 369, 1556-1569, (doi: 10.1098/rsta.2010.0369)
} 
${ }^{16}$ Joslin, R. D. 1998 Aircraft laminar flow control. Annu. Rev. Fluid Mech. 30, 1-29. (doi:10.1146/annurev.fluid.30.1.1)

${ }^{17}$ Hefner, J. N. and Sabo, F. E., "Research in Natural Laminar Flow and Laminar Flow Control," NASA CP-2487, Parts 1-3, 1987

${ }^{18}$ Wagner, R. D.; Barlett, D. W.; and Collier Jr, F. S., "Laminar Flow - the Past, Present, and Prospects," AIAA-89-0989, 1989

${ }^{19}$ Mullender, A. J. and Poll, D. I. A., "Aircraft Drag Reduction: The Application of Natural Laminar Flow to Aero-Engine Nacelles,” ISABE'95, Derby, UK, Oct 1995.

${ }^{20}$ Wagner, R. D.; Maddalon, D. V.; and Fisher, D. F., "Laminar Flow Control Leading Edge Systesm in Simulated Airline Service," Journal of Aircraft, March 1990, 27(3), pp. 239-244.

${ }^{21}$ Henke, R., “ The Airbus A320 HLF Fin Programme,” Nouvelle Revew d'Aeronautique et d'Astronautique, April 1998, 2, pp. 53-55.

${ }^{22}$ Crouch, J. D., "Modeling Transition Physics for Laminar Flow Control," AIAA-2008-3832, 38th AIAA Fluid Dynamics. Conference and Exhibit, Seattle, WA, June 2008.

${ }^{23}$ Norris, G., "787 - Tail Wagging the Dog," Aviation Week, URL

http://www.aviationweek.com/aw/blogs/commercial_aviation/ThingsWithWings/index.jsp?plckController=Blog\&plckScript=blo gScript\&plckElementId=blogDest\&plckBlogPage=BlogViewPost\&plckPostId=Blog\%3A7a78f54e-b3dd-4fa6-ae6e-

dff2ffd7bdbbPost\%3Aef0c1862-a521-4d62-b1b6-b5b58e38a7d8, [cited 12 August 2010]

${ }^{24}$ Saric, W. S., Carpenter, A. L. \& Reed, H. L. 2011 Passive control of transition in threedimensional boundary layers, with emphasis on discrete roughness elements. Phil. Trans. R. Soc. A 369, 1352-1364. (doi:10.1098/rsta.2010.0368)

${ }^{25}$ Saric, W., "Design of the Subsonic Aircraft Roughness Glove Experiment (SARGE)," AIAA-2011-3524, AIAA Applied Aerodynamics Conference, Honolulu, HI, June 2011.

${ }^{26}$ Malik, M., "Computational Analysis of the G-III Laminar Flow Glove," AIAA-2011-3525, AIAA Applied Aerodynamics Conference, Honolulu, HI, June 2011.

${ }^{27}$ Tilmann, C. P., Enhancement of Transonic Airfoil Performance Using Pulsed Jets for Separation Control," AIAA Paper 2001-0731

${ }^{28}$ Milholen, W. and Owens, L., "On the Application of Contour Bumps for Transonic Drag Reduction (invited)," AIAA2005-0462, 43 ${ }^{\text {rd }}$ AIAA Aerospace Sciences Meeting, Jan, 2005.

${ }^{29}$ König, B.; Lutz, T.; Rosemann, H.; Richter, K.; Uhlemann, H., "Numerical and Experimental Validation of ThreeDimensional Shock Control Bumps," Journal of Aircraft, Vol. 46, no. 2, pp. 675-682, 2009.

${ }^{30}$ Wahls, R., "High Speed Slotted Wing Technology," NASA Vehicle Systems Program Annual Meeting, Atlanta, GA, May 2004.

${ }^{31}$ Munk, Max 1923 The Minimum Induced Drag of Aerofoils, NACA TR-121

${ }^{32}$ Cone, C. C. 1962 The Theory of Induced Lift and Minimum Induced Drag of Nonplanar Lifting Systems, NASA TR R-139

${ }^{33}$ Whitcomb, R. T. 1976 A Design Approach and Selected Wind-Tunnel Results at High Subsonic Speeds for Wing-Tip Mounted Winglets, NASA TN D-8260

${ }^{34}$ Jones, R.T. 1950 The Spanwise Distribution of Lift for Minimum Induced Drag of Wings Having a Given Lift and a Given Bending Moment, NACA TN-2249

${ }^{35}$ Gould, J. D. 1985 Effect of Active Control System Nonlinearities on the L-1011-3(ACS) Design Gust Loads

${ }^{36}$ Velicki, A., Thrash, P., Jegley, D., “Airframe Development for the Hybrid Wing Body Aircraft”, AIAA 2009-932, January, 2009.

${ }^{37}$ Taminger, K. M. B.; and Hafley, R. A.: "Electron Beam Freeform Fabrication (EBF ${ }^{3}$ ) for Cost Effective Manufacturing." NASA TM-2006-214284, March 2006.

${ }^{38}$ Kapania, R. K.; Li, J.; and Kapoor, H. ,'Optimal Design Study of Curvilinear Stiffened Panels." AIAA 5th Aviation, Technology, Integration, and Operations Conference (ATIO)/ 16th Lighter-than-Air and Balloon Systems Conference/26 - 28 Sep 2005, Arlington, Virginia.

39 Turner, T.,"Multi-Objective Leading-Edge Concepts for Airframe Noise Reduction," FAP Annual Meeting, September/October 2009, Atlanta, GA.

${ }^{40}$ Kota, S.; Osborn, R.; Ervin, G.; Maric, D.; Flick, P.; and Paul, D., "Mission Adaptive Compliant Wing - Design, Fabrication and Flight Test," RTO-MP-AVT-168 - Morphing Vehicles, Evora, Portugal, April 2009.

41 Gur, Ohad; Schetz, Joseph A.; and Mason, William H.:"Aerodynamic Considerations in the Design of Truss-Braced-Wing Aircraft," AIAA Journal of Aircraft, Vol. 48, No. 3, May-June 2011, pp 919-939.

\section{Copyright Statement}

The authors confirm that they, and/or their company or organization, hold copyright on all of the original material included in this paper. The authors also confirm that they have obtained permission, from the copyright holder of any third party material included in this paper, to publish it as part of their paper. The authors confirm that they give permission, or have obtained permission from the copyright holder of this paper, for the publication and distribution of this paper as part of the $41^{\text {st }}$ AIAA Fluid Dynamics Conference and Exhibit proceedings or as individual offprints from the proceedings. 